\title{
Socio Economic Conditions of Social Work Students
}

\author{
K.Maheswari* and S.Kalaiselvan** \\ * Head, Department of Social Work, Bharathidasan University College, Perambalur, \\ Tamil Nadu, India. \\ ** Doctoral Research Scholar, Department of Social Work, Bharathidasan University College, Perambalur, \\ Tamil Nadu, India.
}

\begin{abstract}
The present study was planned to measure the socio economic conditions of post graduate social work students studying at colleges in Tiruchirappalli district. The study also aimed to measure the interest, attitude of social work students and importance of field work. The individuals were administered a questionnaire to assess their socio-economic condition with 45 items. Descriptive research design was adopted for the study. The universe of the study compels of 345 students pursuing post graduate in social work and questionnaires were administered to the respondents and census method was used for the study. Out of 345 participants, 302 of them have respondent to the study. The data was analyzed and explained using frequency table. It was found that 59.9 per cent of the respondents were female and majority of them (64\%) were hailing from rural areas. A significant member $(38.4 \%)$ of their family income is up to 10000 per month and great majority of them $(87.1 \%)$ are dependent on their families for their expenses.
\end{abstract}

Keyword:- Student, Socio-economic, Social Work,

\section{INTRODUCTION}

Social work education is a phenomenon of the twentieth century. Social works prominence among the professions results from community demands for trained staff to administer a multibillion dollar human service system. Society has declared that the work of helping people with personal and social problems must be handled with professional competence and subjected to rigorous tests of accountability. Early schools trained workers for jobs in specific agencies. But in a mobile society, social work graduates are on the go, and their education needs to be applicable to all situations. Social work practices embraces multiple methods and models, including generalist practice and a variety of concentrations defined of classification. Social work practice occurs with individuals, families, small groups, organizations, and communities. This variety and range represent the current state of the art in social work practice. The curriculum contents relating to practice must include the knowledge base, i.e./ theory, research, and practice wisdom. It must also include the practice skills, i.e., exploration and data gathering differential assessment and differential planning, intervention, and evaluation relevant to social work practice Chaturvedi (2005).

Social work profession certainly has made impressive advancement in different areas but the overall progress of social work profession in India is reflected mainly in terms of growth in number of institutions offering social work education and not in quality with reference to professionalism. It is painful to observe that the accomplishment of social work profession of India is neither satisfying nor appreciable when compare with situations in developed, poor and developing nations of the globe. Social work students undergo field work that exposes them to poverty, lack of basic amenities to poverty groups, discrimination against women and children, and older and other vulnerable groups in the community and this enables them to link their theoretical knowledge with the field and learn to practice social work principles and methods in the real world observes Anand(2009). The generic social work course in the state is now an extinct phenomenon and the specializations oriented system is in vogue at the Master's level. The specialization orientation of all social work programmers in the state is so firmly entrenched that it seems more feasible to modify and enrich the system rather than abort it and revert to the generic orientation advocated by leading academics such as Desai (1994). Interpretations of the social work supervision with students in practical training Social work supervision with students is perceived as a constant process, in which the learning young specialists get guidelines, support, gain experience, study and overcome difficulties and challenges in practical situations Nunev (2014).

\section{REVIEW OF LITERATURE}

Urdang (2010) has critically analyzed the application of self-awareness to all levels of clinical practice, and its reflection among the social work students. The researcher has insisted that, students need guidance in becoming aware of their own feelings, attitudes and relationships with clients and these are the 
major factors in the helping process in all service settings. The researcher has also suggested that reclaiming psychodynamic theories; emphasizing self-awareness academically and practically in the field; utilizing process recording will provide better opportunities for students.

Litvacic et.al (2010) described the students' emotional reactions to experiences in field education. Significant and interrelated themes emerged including the subjective and unique definitions of emotionally charged events; the considerable effect of the student-field instructor relationship and the organizational environment, whereby both act as major risk and major protective factors participants seeking help from sources in their family and social networks and not necessarily from those in formal social work education roles.

Erbay and Akçay (2013) study reviled as assertiveness skill of social work students: a case of turkey research has been conducted with 1st and 4th grade students (n: 198) who are studying in Social Work Department at Hacettepe University. The assertiveness skills scale of Rathus has been used to obtain data. According to summed results it has been noticed that the social work education has not increased the assertiveness skills, 1st grade students are being more assertive than 4 th grade students, male students are being more assertive than female students and assertiveness level of students is reduced when the income of their families increased. Consequently, this research is considered to contribute to the social work literature.

Nunev (2014) has examined the supervision practical training problems with social work students. The researcher has specified the supervision design with particular patterns, organization and implementation and has concluded that detailed analysis of problems, practical learning and experience will contribute for higher quality of education and supervision.

Aim

The aim of the study is to assess the socio-economic conditions of post graduate social work students studying at colleges in Tiruchirappalli district.

Objectives

* To understand the socio economic conditions of the sample population.

* To know about the interest and future plan of the respondents

* To assess the development achieved through social work profession.

\section{MATERIALS AND METHODS}

Study population: the study population consists of all post graduate social work students studying at colleges of Tiruchirapalli district. The colleges have admitted students in MSW degree course and the enrollment list was obtained from the colleges regarding social work students the universe of the study compels of 345 students pursuing post graduate in social work Out of 345 participants, 302 of them have respondent to the study. Questionnaires were distributed to them and data was collected. Census method was adopted to collect the data from the respondents. Research design: since the study tries to understand the socio economic conditions of social work students, the research design opted for this study is descriptive in nature. Tools: due to the time limitation to develop, test and validate a questionnaire to assess the socio economic conditions, a self prepared questionnaire was used to collect the data on socio economic conditions, future plan, and the interest towards the course by the respondents. It consists of 45 items. Frequency tables were used to interpret the data.

\section{FINDINGS AND DISCUSSION}

The major findings of the study have been explained in depth. Considering the gender of the social worker in India is most commonly a women (ejaz,1991) and gender imbalance has not changed even today and the same situation has been observed in UK also (stanley, 2009) The mean age of the study population is 21 years and majority of the respondents were female (59.9\%). More than half of the respondents were living in rural areas whereas 46 per cent of them are from urban setting. Vast majority of them (93\%) were unmarried and only 7 per cent were married. Majority of the respondents (66.2\%) were following Hinduism, 28.2 per cent were Christians and only 5.6 per cent were from Islamic religion. Majority of them were living with joint families (72.2\%) and their family size includes 4 to 6 members. In terms of ethnicity, around half of the respondents belonged to the open category and equal proportion of the respondents $(22.2 \%)$ belonged to backward classes $(22.2 \%)$ and under privileged sections of the society. 47 per cent where coming from their own houses, 36.8 per cent are staying at hostels to get higher education and only few of them (2.6\%) are staying in relative house.

\section{ECONOMIC STATUS OF THE RESPONDENTS}

When considering the economic conditions of the respondents, nearly majority of the respondents' $(58.9 \%)$ where living in concrete houses and 30.5 per cent where residing in huts. In terms of economic dependence, 
majority of the respondents $(87.1 \%)$ were fully dependent on their families for expenses because all were students and 12.9 per cent were employed in part-time jobs. A significant number (38.4\%) of the respondents family income is up to Rs. 10,000 per month, 31.1 per cent of their family income was in between Rs.10,000 and 20,000, and 15.9 per cent of them have said that their family income is between Rs.20,000 to 30,000, and 14.5 per cent of the respondent family income is above Rs.30,000. Majority of the respondents (64.9\%) have saving habit and they save in banks and in piggy pots at home. Nearly half of the respondents (48.7\%) have said that they spent most of the amount for mobile usage, followed by transportation (26.8\%), food (15.2\%) and 10.3 per cent medical.

\section{Educational Qualification, reading habit, and leisure time activities}

Among the surveyed social work students, a significant per cent of them (39.7\%) have been educated in government schools, whereas 28.8 per cent have studied in private institutions, and 31.5 per cent in aided schools. It is noteworthy that majority of respondents $(59.5 \%)$ where first graduates in their family and majority of them (61.9\%) have done their bachelors degree from aided colleges. It is found that, majority of the respondents (64.2\%) do not have fluency in English language and writing skills. The communication barrier has made them to stagnate in certain areas and it is also has an impact on personality, confidence and execution of skills. The medium of instruction is English and the students find difficulty in report writing, documentation and research.

Regarding the reading habit, majority of them (77.2\%) are using library for reference work. But the choice of reading sources among the respondents were news papers (47.4\%), academic books (27.4\%) magazines and novel (12.6\%). Regarding the respondent's parent educational qualification, nearly half of them respondents father $(46.4 \%)$ and mother $(48 \%)$ where educated up to primary level, whereas 23.8 per cent of the respondents father and 19.5 per cent of mothers were illiterates. It is also found that 46 per cent of them have chosen social work course by themselves, by parents (10.3\%), teachers (17.2\%) relatives (7.5\%) and friends (19.2\%). Majority of the respondents (65.9\%) are from cross majors and only 29.1 per cent have done UG in social work discipline. It is also interesting to know that majority of the respondents were female.

When analyzing the additional qualification of the respondents, majority of them (70.2\%) have done computer courses, type writing (10.9\%) and 12.6 per cent have done diploma courses. Regarding the leisure time activities, 52.6 per cent were interested in watching television, chatting with friends (25.8\%), listening radio $(12.9 \%)$ and only 8.6 per cent of them are interested in games. From the study, it is clear that great majority of the respondents are inactive and don't give importance to physical activity.

It is observed from the study that, majority of the respondents $(60 \%)$ extracurricular activity includes dancing, singing and involving in cultural and 40 per cent of them are interested in sports.

\section{Opinion and Interest in Social Work Course}

Majority of the respondents have welcomed the course because of the field work practicum and job opportunities in various settings. When coming to the choice of the specialization 33.5 per cent prefer human resource management, whereas 31.4 per cent prefer medical and psychiatry and the remaining respondents preferred community development specialization.

\section{Personal Development of Social Work Students}

Evaluation of the personal growth of the respondents showed that all the respondents have achieved growth in one or other aspects. Majority of them feel that there has been change occurring in their personality $(80.2 \%)$, attitudinal change and broadmindedness, skill development to seek jobs and dealing with crisis situation, problem solving and confidence. It is also interesting to know that 34.01 per cent have said they have emotionally matured, and have sound mental health to lead a refined quality of life.

\section{Importance of Field Work}

It is noted that vast majority of the respondents (93\%) were aware of field work as core content of social work course. Field work has enhanced their knowledge and has provided opportunity to apply theory and practice. But the students from rural areas find it difficult to travel long for the agencies, apply skills, some of the agencies don't have qualified staff to train the social work students, and poor supervision procedure. Economic conditions decides the effective performance of students and attitude of students towards field work has also changed, lack of commitment, sincerity, lack of learning aspiration etc. Unless field work is achieved to the fullest the social work students will not be able to withstand in their career and future aspects.

Finally it is noteworthy about the social work students future plan, 42.4 per cent of them have said that they will be placed in recognized job and 22.2 per cent of them have said that they have not yet decided about their future, 14.2 per cent are interested to become philanthropist, and equal number of them have (10.6\%) said they will get married and do higher studies. 


\section{CONCLUSION}

Researchers have shown significant interests on professionalization, social work programmes, importance of field work, syllabus and career development but there is lacunae in the area of social work student's welfare, procedure of enrolment, quality enhancement among social work students and dilution of the course though distance mode. A few things that are of paramount importance for successful social work professionals are the maintenance of individuality, functioning ability, updating of knowledge and skill development. This study shows that socio economic conditions play a vital role in producing quality social work and education the research study also reveals that the confidence and commitment must be given utter importance to become a qualified professional.

\section{REFERENCES}

[1] Pratima Chaturvedi 2005. Social Work Theories and Practices Published by book enclave jaipur roshan offset printers delhi ISBN 8181521226 pp 244-247.

[2] Nunev Sasho 2014. Supervision Practical Training Problems With Social Work Students Trakia Journal of Sciences, Vol. 12, Suppl. 1, pp 461-466,

[3] Anand.M.(2009). Gender in social work education and practice in India. Social work education, 28, 96106.

[4] Desai.As. (1980). Social work education in India, ministry of welfare, New Delhi.

[5] Sambangi.D. (2009). The Social Work profession in India: progress problems and prospects. Quality enhancement of social work profession in India Issues and challenges Edited by P.Ilango. Published by Allied publisher pvt.ltd.

[6] Ejaz.F.K. (1991). Self determination: lessons to be learned from social work practice in India, British Journal of Social work, 21. 127-142.

[7] Selwyn Stanley. (2009). The Social Work profession in India: progress problems and prospects. Quality enhancement of social work profession in India Issues and challenges Edited by P.Ilango. Published by Allied publisher pvt.ltd.

[8] Esther Urdang.(2010) Awareness of self - a critical tool: Social Work Education Vol. 29, No. 5, August 2010, pp. 523-538.

[9] Andrea Litvacic , Marion Bogo and faye Mishna. (2010).Emotional Reactions of Students in Field Education: An Exploratory Study Journal of Social Work Education, Vol. 46, No. 2, Spring/Summer 2010.

[10] Ercument Erbay And Sinan Akcay. (2013). assertiveness skill of Social Work Students: A Case of Turkey, Academic Research International Journal Vol. 4, No. 2, pp.316-323. 